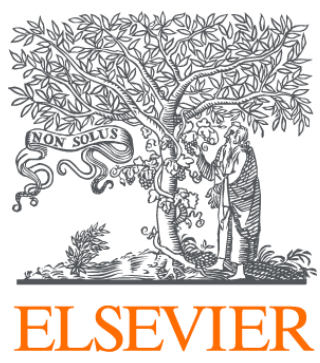

Since January 2020 Elsevier has created a COVID-19 resource centre with free information in English and Mandarin on the novel coronavirus COVID-

19. The COVID-19 resource centre is hosted on Elsevier Connect, the company's public news and information website.

Elsevier hereby grants permission to make all its COVID-19-related research that is available on the COVID-19 resource centre - including this research content - immediately available in PubMed Central and other publicly funded repositories, such as the WHO COVID database with rights for unrestricted research re-use and analyses in any form or by any means with acknowledgement of the original source. These permissions are granted for free by Elsevier for as long as the COVID-19 resource centre remains active. 


\title{
American Journal of \\ Preventive Medicine
}

RESEARCH ARTICLE

\section{Willingness to Vaccinate Against COVID-19 in the U.S.: Representative Longitudinal Evidence From April to October 2020}

\author{
Michael Daly, $\mathrm{PhD},{ }^{1}$ Eric Robinson, $\mathrm{PhD}^{2}$
}

Introduction: Vaccines against COVID-19 have been developed in unprecedented time. However, the effectiveness of any vaccine is dictated by the proportion of the population willing to be vaccinated. This observational population-based study examines intentions to be vaccinated against COVID-19 throughout the pandemic.

Methods: In November 2020, longitudinal data from a nationally representative sample of 7,547 U.S. adults enrolled in the Understanding America Study were analyzed using multinomial logistic regression. Participants reported being willing, undecided, and unwilling to get vaccinated against COVID-19 across 13 assessments conducted from April to October 2020. Public attitudes to vaccination against COVID-19 were also assessed on a 4-point Likert-type scale.

Results: Willingness to vaccinate declined from $71 \%$ in April to $53.6 \%$ in October. This was explained by an increase in the percentage of participants undecided about vaccinating (from $10.5 \%$ to $14.4 \%$ ) and the proportion of the sample unwilling to vaccinate (from $18.5 \%$ to $32 \%$ ). The population subgroups most likely to be undecided/unwilling to vaccinate were those without a degree (undecided: $\mathrm{RR}=2.47,95 \% \mathrm{CI}=2.04$, 3.00; unwilling: $\mathrm{RR}=1.92,95 \% \mathrm{CI}=1.67,2.20$ ), Black participants (undecided: $\mathrm{RR}=2.18,95 \% \mathrm{CI}=1.73,2.74$; unwilling: $\mathrm{RR}=1.98,95 \% \mathrm{CI}=1.63,2.42$ ), and female participants (undecided: $\mathrm{RR}=1.41,95 \% \mathrm{CI}=1.20,1.65$; unwilling: $\mathrm{RR}=1.29,95 \% \mathrm{CI}=1.14$, 1.46). Participants who were older or were on higher incomes were least likely to be undecided or unwilling to vaccinate. Concerns about potential side effects of a vaccine were common.

Conclusions: Intentions to be vaccinated against COVID-19 have declined rapidly during the pandemic, and close to half of Americans are undecided or unwilling to be vaccinated.

Am J Prev Med 2021;60(6):766-773. @ 2021 American Journal of Preventive Medicine. Published by Elsevier Inc. This is an open access article under the CC BY license (http://creativecommons.org/licenses/by/4.0/).

\section{INTRODUCTION}

$\Lambda$ $\mathrm{s}$ of the middle of February 2021, the coronavirus disease 2019 (COVID-19) pandemic has been responsible for $>2.3$ million deaths worldwide. ${ }^{1}$ Vaccines against severe acute respiratory syndrome coronavirus 2 (SARS-CoV-2) have been developed in an unprecedented time, and there are now multiple vaccines that have been shown to be effective in preventing symptomatic COVID-19 infections. ${ }^{2}$ The U.S. Food and Drug Administration (FDA) has issued emergency use authorization for the mass roll out of the Pfizer-BioNTech and Moderna COVID-19 vaccines, ${ }^{3}$ and other candidates may be approved for distribution in the near future. However, the overall effectiveness of any vaccine is dictated, at least in part, by the proportion of the population willing to be vaccinated. Simulation studies suggest that at least three quarters of the population may need to be vaccinated to extinguish the ongoing COVID-19 pandemic. ${ }^{4,5}$

From the ${ }^{1}$ Department of Psychology, Maynooth University, Kildare, Ireland; and ${ }^{2}$ Institute of Population Health Sciences, University of Liverpool, Liverpool, United Kingdom

Address correspondence to: Michael Daly, PhD, Department of Psychology, Maynooth University, 1.1.7 Education House, Maynooth, Ireland. E-mail: michael.a.daly@mu.ie.

$0749-3797 / \$ 36.00$

https://doi.org/10.1016/j.amepre.2021.01.008 
During the early stages of the pandemic (March-June), studies of small samples of European and Australian adults suggested that the majority of surveyed people reported that they would be vaccinated when a widely available vaccine was available. ${ }^{6,7}$ Similarly, a nationally representative study of adults in China conducted in March found that 9 in 10 persons would accept a vaccine when available. ${ }^{8} \mathrm{U}$. S. studies conducted early in the pandemic found that between $58 \%$ and $86 \%$ of adults reported that they were likely to be vaccinated against COVID-19., ${ }^{6,-11}$

However, the rise of fake news during the pandemic has been widely acknowledged, ${ }^{11,12}$ and widespread misinformation about the pandemic may have been damaging to the public uptake of measures designed to reduce the spread of the virus (e.g., mask wearing, social distancing) and the willingness to vaccinate. ${ }^{10,13,14}$ In addition, because the speed at which COVID-19 vaccines have been developed has been unparalleled and this has been widely reported, ${ }^{2,3}$ this may have made the public more hesitant about accepting a vaccine when available. ${ }^{15,16}$ Furthermore, research indicates that in some countries, the public trust in government handling of the COVID-19 crisis has been affected negatively, ${ }^{17}$ and this too may have detrimentally affected intentions to follow public health guidance.

The COVID-19 pandemic has had a disproportionately large impact on ethnic minorities ${ }^{18}$ and groups from lower socioeconomic backgrounds, ${ }^{19}$ and as infections will likely continue to be socially patterned, understanding whether population demographics determine the willingness to vaccinate will also be important. For example, research examining previous influenza vaccination programs has found that vaccination intentions and uptake are reduced among more disadvantaged groups. ${ }^{20,21}$ Initial research examining COVID-19 vaccination intentions has produced mixed findings on the role of demographic predictors, which may be due to a reliance to date on relatively small and nonrepresentative samples. ${ }^{9,10,22}$

This study examines the estimates of the proportion of the U.S. general population that would be willing to use a vaccine when available. In addition, this study examines whether the estimates of vaccination uptake collected much earlier in the pandemic have changed over time. Furthermore, this study seeks to understand whether the intentions to vaccinate are socially patterned and more or less likely in specific population subgroups. This information will provide an empirical basis for directing public health messages at those who are least likely to vaccinate. ${ }^{15,16}$ To do this, this research made use of data from the Understanding America Study (UAS), a large nationally representative panel of U.S. adults who have reported their vaccine intentions on 13 occasions from the outbreak of the pandemic through October 2020.

\section{METHODS}

\section{Study Sample}

This study utilized data collected as part of the UAS, a nationally representative longitudinal study of adults aged $\geq 18$ years. The UAS is a probability-based sample recruited through addressbased sampling from the U.S. Postal Service Computerized Delivery Sequence file containing all U.S. postal addresses. ${ }^{23}$ Participants complete surveys online, and those without Internet access are provided with tablet computers and Internet access. Surveys were administered in English and Spanish, and participants were compensated with approximately $\$ 20$ for 30 minutes of survey time. $^{24}$ Of 8,547 UAS participants eligible to take part in the COVID-19 tracking study, 7,547 participated and provided data. The UAS COVID-19 tracking study has been utilized to examine the changes in personal and social reactions, risk perception, ${ }^{25,26}$ and mental health ${ }^{27}$ in response to the pandemic. Vaccination intentions were assessed in 13 of the 15 waves of the assessment conducted every 2 weeks between April 1, 2020 and October 31, $2020 .^{24}$ The number of participants and observations per survey month are shown in Appendix Table 1 (available online). The percentage of participants providing willingness to vaccinate data was lowest in June (74.1\%) and relatively stable in other months (ranging from $81.8 \%$ to $88.1 \%$ ) (Appendix Table 1, available online).

In total, participants provided 80,060 observations across the 13 survey waves (average response rate of $81.6 \%$ among COVID-19 tracking study participants). A small portion (2\%) of observations were omitted because they were submitted after October 31 or were missing vaccination intentions or covariate data, leaving a total of 78,453 observations (10.4 per participant). The UAS weights were applied to adjust for unequal probabilities of selection into the UAS. Post-stratification weights were also incorporated to provide a correction for nonresponse by aligning each survey wave with the distribution of demographic characteristics of the U.S. population (Angrisani M, Center for Economic and Social Research (CESR), unpublished observations, 2019).

The UAS was approved by the University of Southern California Human Subjects Committee IRB, and informed consent was obtained from all participants (through computer link). The Maynooth University Social Research Ethics Sub-Committee does not require ethical approval to be granted for the secondary use of anonymous data, such as the data used in this study.

\section{Measures}

In each survey wave, participants indicated how likely there were to get vaccinated for COVID-19 when a vaccine becomes available to the public on a 5-point scale. Participants were classified as either (1) undecided (responses of unsure), (2) unwilling to vaccinate (responses of somewhat or very unlikely to vaccinate), or (3) willing to vaccinate (responses of somewhat or very likely to vaccinate).

Vaccination intentions were predicted by the month of the survey (April, May, June, July, August, September, and October) and a set of demographic variables: age (18-34, 35-44, 50-64, $\geq 65$ years), sex (male, female), race/ethnicity (White, Hispanic, Black, other race/ethnicity), household income ( $\leq \$ 40,000 / \$ 40,000-\$ 100,000 /$ $\geq \$ 100,000$ gross per annum), college degree (versus none), and the presence of a chronic health condition (present versus not present). Specifically, participants indicated whether they had been diagnosed with the following conditions: diabetes, cancer, heart disease, kidney disease, asthma, chronic lung disease, or an autoimmune disease. 
Table 1. Attitudes Toward Vaccination Against COVID-19 in the Understanding America Study Assessed Between October 14, 2020 and October 31, $2020(\mathrm{~N}=5,762)$

\begin{tabular}{|c|c|c|c|c|c|c|c|c|}
\hline \multirow[b]{2}{*}{ Question $^{\mathrm{a}}$} & \multicolumn{2}{|c|}{ Full sample } & \multicolumn{2}{|c|}{ Willing to vaccinate ${ }^{b}$} & \multicolumn{2}{|c|}{$\begin{array}{l}\text { Undecided on } \\
\text { vaccination }^{\text {b }}\end{array}$} & \multicolumn{2}{|c|}{$\begin{array}{l}\text { Unwilling to } \\
\text { vaccinate }^{b}\end{array}$} \\
\hline & Agree (\%) & Disagree (\%) & Agree (\%) & Disagree (\%) & Agree (\%) & Disagree (\%) & Agree (\%) & Disagree (\%) \\
\hline $\begin{array}{l}\text { The COVID vaccine will be } \\
\text { important for my health. }\end{array}$ & 71.2 & 28.8 & 93.8 & 6.2 & 69.1 & 30.9 & 33.7 & 66.3 \\
\hline $\begin{array}{l}\text { Getting a COVID vaccine } \\
\text { would be a good way to } \\
\text { protect me from } \\
\text { coronavirus disease. }\end{array}$ & 74.2 & 25.8 & 95.4 & 4.6 & 71.6 & 28.4 & 39.3 & 60.7 \\
\hline $\begin{array}{l}\text { The COVID vaccine will be } \\
\text { effective if it is approved } \\
\text { by the FDA or CDC. }\end{array}$ & 73.7 & 26.3 & 92.4 & 7.6 & 71.0 & 29.0 & 43.1 & 56.9 \\
\hline $\begin{array}{l}\text { Getting the COVID vaccine } \\
\text { will be important for the } \\
\text { health of others in my } \\
\text { community. }\end{array}$ & 79.4 & 20.6 & 96.1 & 3.9 & 77.7 & 22.3 & 51.7 & 48.3 \\
\hline $\begin{array}{l}\text { The COVID vaccine will be } \\
\text { beneficial to me. }\end{array}$ & 73.8 & 26.2 & 95.1 & 4.9 & 74.3 & 25.7 & 37.4 & 62.6 \\
\hline $\begin{array}{l}\text { I will do what my doctor or } \\
\text { health care provider } \\
\text { recommends about the } \\
\text { COVID vaccine. }\end{array}$ & 74.5 & 25.5 & 92.8 & 7.2 & 70.9 & 29.1 & 44.7 & 55.3 \\
\hline $\begin{array}{l}\text { The COVID vaccine will not } \\
\text { be around long enough to } \\
\text { be sure it is safe. }\end{array}$ & 48.1 & 51.9 & 39.9 & 60.1 & 58.8 & 41.2 & 57.3 & 42.7 \\
\hline $\begin{array}{l}\text { I am concerned about } \\
\text { serious side effects of the } \\
\text { COVID vaccine. }\end{array}$ & 69.7 & 30.3 & 60.6 & 39.4 & 81.4 & 18.6 & 80.2 & 19.8 \\
\hline $\begin{array}{l}\text { I think the COVID vaccine } \\
\text { might cause lasting health } \\
\text { problems for me. }\end{array}$ & 43.6 & 56.4 & 26.6 & 73.4 & 61.5 & 38.5 & 65.0 & 35.0 \\
\hline
\end{tabular}

Note: Estimates are based on weighted data.

${ }^{a}$ Each item was rated on a 4-point scale, with those responding Somewhat or Strongly agree coded as Agree and those responding Somewhat or Strongly disagree coded as Disagree.

${ }^{\mathrm{b}}$ Based on responses to the question: How likely are you to get vaccinated for coronavirus once a vaccine is available to the public? In this survey wave (responses between October 14, 2020 and October 31, 2020), 54\% of the sample were classified as willing to vaccinate, 14\% were classified as undecided, and $32 \%$ were classified as unwilling to vaccinate.

CDC, Centers for Disease Control and Prevention; FDA, U.S. Food and Drug Administration.

Participants also reported their level of agreement (from $1=$ strongly disagree to $4=$ strongly agree), with 9 items assessing their attitudes toward a potential vaccine (Table 1 provides items in full) in late October (October 14-31). Questions assessed the participant's beliefs that the COVID-19 vaccine would be beneficial, important for personal and community health, and a good way to protect from COVID-19. Participants also indicated whether they agreed that approved vaccines would be effective and whether they were concerned about the lack of long-term follow-up information, and potential side effects of a COVID-19 vaccine were assessed (e.g., I think the COVID-19 vaccine might cause lasting health problems for me).

\section{Statistical Analysis}

First, investigators examined the trends in vaccination intentions over the period of the study by comparing the prevalence of willingness/being undecided/unwillingness to vaccinate in April and
October 2020. To estimate the statistical significance of time trends, multinomial logistic regression analysis ${ }^{28}$ was used with robust SEs clustered at the individual level. Those willing to vaccinate were compared with (1) those undecided on vaccination and (2) those unwilling to vaccinate. A series of multinomial logistic regressions were run to identify whether the relative risk (RR) of being undecided or unwilling to vaccinate increased from April to October for the overall sample and for each examined population subgroup. This model contrasts the natural log (Probability [Pr] [unwilling to vaccinate] $/ \operatorname{Pr}$ [willing to vaccinate]) and the natural $\log (\operatorname{Pr}[$ undecided on vaccination]/Pr[willing to vaccinate]) estimates across different demographic groups to ascertain relative risk ratios (RRRs).

Next, multinomial logistic regression was used to estimate the extent to which survey month and different demographic factors predicted vaccination intentions. A single adjusted analysis was used to estimate the independent effect of each predictor variable (i.e., month of the survey, age, sex, race/ethnicity, educational 
attainment, income, presence of a chronic condition) controlling for all others. In addition, the authors tested a separate model where interactions between survey month and participant demographics were added to the main model to test whether changes in vaccination intentions over time differed systematically between demographic groups. Finally, in a supplementary sensitivity analysis, the willingness to vaccinate was treated as a continuous outcome (ranging from $1=v e r y$ likely to vaccinate to $5=v e r y$ unlikely to vaccinate) examined using ordinary least squares regression with SEs clustered at the individual level.

All analyses incorporated the UAS sampling weights to generate nationally representative estimates. RRRs and 95\% CIs were estimated using the Stata, version 15.

\section{RESULTS}

Participants were aged $47.2(\mathrm{SD}=16.6)$ years on average; $52.1 \%$ of them were female; $34.2 \%$ had a college degree; and $64.1 \%$ were White, $17.8 \%$ were Hispanic, $12.2 \%$ were Black, and 5.9\% were Other race/ethnicity (Table 2). On average, willingness to vaccinate declined from $71 \%$ in April to $53.6 \%$ in October. This was explained by an increase in the percentage of participants undecided about vaccinating against COVID-19 (from 10.5\% to $14.4 \%$ ) and the portion of the sample unwilling to vaccinate (from $18.5 \%$ to $32 \%$ ) (Table 2 ). A decrease in the willingness to vaccinate against COVID-19 between April and October was evident across all examined population subgroups (Table 2).

An unadjusted multinomial logistic regression analysis confirmed that from April to October 2020, there was a statistically significant higher risk of being undecided $(\mathrm{RRR}=1.82,95 \% \mathrm{CI}=1.62,2.05)$ or unwilling $(\mathrm{RRR}=2.29,95 \% \mathrm{CI}=2.11,2.48)$ to be vaccinated than being willing to get vaccinated (Appendix Table 2,

Table 2. Sample Characteristics of Participants in the UAS $(N=7,547$, Obs. $=78,453)$ and Vaccination Intentions in April and October 2020

\begin{tabular}{|c|c|c|c|c|c|c|c|}
\hline \multirow[b]{2}{*}{ Variables } & \multirow[b]{2}{*}{ Sample size (\%) } & \multicolumn{2}{|c|}{ Willing to vaccinate ${ }^{a}$} & \multicolumn{2}{|c|}{ Undecided on vaccination $^{a}$} & \multicolumn{2}{|c|}{ Unwilling to vaccinate } \\
\hline & & $\begin{array}{c}\text { April, } \\
\%\end{array}$ & $\begin{array}{c}\text { October, } \\
\%\end{array}$ & $\begin{array}{c}\text { April, } \\
\%\end{array}$ & $\begin{array}{c}\text { October, } \\
\%\end{array}$ & $\begin{array}{c}\text { April, } \\
\%\end{array}$ & $\begin{array}{c}\text { October, } \\
\%\end{array}$ \\
\hline Overall sample & & 71.0 & 53.6 & 10.5 & 14.4 & 18.5 & 32.0 \\
\hline \multicolumn{8}{|l|}{ Age group, years } \\
\hline $18-34$ & $2,024(26.8)$ & 65.6 & 47.2 & 12.9 & 16.2 & 21.5 & 36.6 \\
\hline $35-49$ & 2,305 (30.5) & 67.5 & 49.6 & 11.5 & 15.5 & 21.0 & 34.9 \\
\hline $50-64$ & $1,832(24.3)$ & 73.1 & 54.2 & 10.6 & 15.1 & 16.3 & 30.7 \\
\hline$\geq 65$ & $1,386(18.4)$ & 79.9 & 65.9 & 6.0 & 10.0 & 14.1 & 24.0 \\
\hline \multicolumn{8}{|l|}{ Sex } \\
\hline Male & $3,613(47.9)$ & 75.1 & 60.0 & 8.2 & 11.7 & 16.7 & 28.3 \\
\hline Female & $3,934(52.1)$ & 67.2 & 47.6 & 12.7 & 17.0 & 20.1 & 35.4 \\
\hline \multicolumn{8}{|l|}{ Race/ethnicity } \\
\hline White & $4,840(64.1)$ & 74.7 & 57.3 & 8.6 & 13.0 & 16.7 & 29.7 \\
\hline Hispanic & $1,345(17.8)$ & 67.4 & 47.5 & 12.2 & 16.2 & 20.5 & 36.3 \\
\hline Black & $917(12.2)$ & 47.9 & 33.8 & 22.0 & 21.8 & 30.1 & 44.3 \\
\hline Other race/ethnicity & $445(5.9)$ & 86.5 & 68.6 & 4.0 & 11.1 & 9.5 & 20.4 \\
\hline \multicolumn{8}{|l|}{ Education } \\
\hline No degree & 4,969 (65.8) & 65.7 & 45.1 & 13.1 & 18.2 & 21.2 & 36.7 \\
\hline College degree & $2,578(34.2)$ & 81.4 & 68.9 & 5.4 & 7.8 & 13.2 & 23.4 \\
\hline \multicolumn{8}{|l|}{ Income level $^{\mathrm{b}}$} \\
\hline Low income & $2,884(38.2)$ & 64.1 & 43.6 & 15.6 & 21.4 & 20.3 & 35.0 \\
\hline Middle income & 3,007 (40.4) & 71.6 & 55.0 & 8.6 & 12.1 & 19.8 & 33.0 \\
\hline High income ${ }^{b}$ & 1,656 (21.9) & 81.1 & 66.9 & 5.6 & 7.8 & 13.3 & 25.4 \\
\hline \multicolumn{8}{|l|}{ Chronic condition $^{\mathrm{C}}$} \\
\hline No & $5,060(67.0)$ & 69.5 & 52.5 & 10.6 & 14.2 & 19.9 & 33.4 \\
\hline Yes & $2,446(32.4)$ & 74.1 & 55.8 & 10.3 & 14.9 & 15.6 & 29.2 \\
\hline
\end{tabular}

Note: Weighted demographic characteristics and vaccination intentions are presented.

${ }^{a}$ Based on responses to the question: How likely are you to get vaccinated for coronavirus once a vaccine is available to the public?

${ }^{\mathrm{b}}$ Households earning $<\$ 40,000$ a year were classified as low income, those earning $\$ 40,000-\$ 100,000$ were classified as middle income, and those above this threshold were classified as high income.

${ }^{c}$ Diagnosed with any of the following: diabetes, cancer, heart disease, kidney disease, asthma, chronic lung disease, and an autoimmune disease. A total of 41 participants did not provide chronic illness data and were included using a missing data dummy.

Obs., observations; UAS, Understanding America Study. 
available online). Unadjusted multinomial logistic regression analyses also showed that all population subgroups were more likely to be undecided or unwilling to vaccinate in October than in April (Appendix Table 2, available online). There was also a greater than 2 -fold higher relative likelihood of being undecided or unwilling to get the COVID-19 vaccine in October than in April 2020 (undecided: RRR=2.03, 95\% $\mathrm{CI}=1.79, \quad 2.29$; unwilling: $\mathrm{RRR}=2.47, \quad 95 \%$ $\mathrm{CI}=2.27,2.68)$ in a fully adjusted model that included controls for participant demographic factors and the presence of chronic illness (Table 3). An examination

Table 3. Results of the Adjusted Multinomial Logistic Regression Analyses Examining Demographic Predictors and Temporal Changes in Indecision and Unwillingness to Vaccinate Against COVID-19 in the U.S. $(\mathrm{N}=7,547$, Obs. $=78,453$ )

\begin{tabular}{|c|c|c|}
\hline Variables & $\begin{array}{l}\text { Undecided on } \\
\text { vaccination, } \\
\operatorname{RRR}^{\text {a }}(95 \% \mathrm{Cl})\end{array}$ & $\begin{array}{c}\text { Unwilling to } \\
\text { vaccinate, } \\
\text { RRR }^{\text {a }}(95 \% \mathbf{C I})\end{array}$ \\
\hline \multicolumn{3}{|l|}{ Month (ref=April) } \\
\hline May & $\mathbf{1 . 2 7 ^ { * * * }}(1.15,1.41)$ & $1.54^{* * *}(1.44,1.66)$ \\
\hline June & $1.34^{* * *}(1.18,1.52)$ & $1.65^{* * *}(1.51,1.80)$ \\
\hline July & $\mathbf{1 . 4 7}^{* * *}(1.30,1.67)$ & $1.76^{* * *}(1.62,1.91)$ \\
\hline August & $1.50^{* * *}(1.33,1.68)$ & $1.97^{* * *}(1.82,2.13)$ \\
\hline September & $1.92^{* * *}(1.70,2.16)$ & $\mathbf{2 . 3 4}{ }^{* * *}(2.16,2.55)$ \\
\hline October & $\mathbf{2 . 0 3}^{* * *}(1.79,2.29)$ & $\mathbf{2 . 4 7} \mathbf{7}^{* * *}(2.27,2.68)$ \\
\hline \multicolumn{3}{|c|}{ Age group, years (ref=18-34) } \\
\hline $35-49$ & $1.07(0.87,1.33)$ & $1.02(0.85,1.21)$ \\
\hline $50-64$ & $0.88(0.71,1.09)$ & $\mathbf{0 . 8 1} *(0.68,0.97)$ \\
\hline$\geq 65$ & $\mathbf{0 . 4 9}^{* * *}(0.38,0.63)$ & $\mathbf{0 . 6 1}^{* * *}(0.51,0.74)$ \\
\hline \multicolumn{3}{|l|}{ Sex $(r e f=m a l e)$} \\
\hline Female & $\mathbf{1 . 4 1}^{* * *}(1.20,1.65)$ & $1.29^{* * *}(1.14,1.46)$ \\
\hline \multicolumn{3}{|c|}{ Race/ethnicity (ref=White) } \\
\hline Hispanic & $1.05(0.82,1.35)$ & $1.02(0.84,1.25)$ \\
\hline Black & $\mathbf{2 . 1 8 ^ { * * * }}(1.73,2.74)$ & $1.98^{* * *}(1.63,2.42)$ \\
\hline Other race/ethnicity & $\mathbf{0 . 5 7 ^ { * * }}(0.40,0.82)$ & $\mathbf{0 . 5 2} \mathbf{2}^{* * *}(0.39,0.71)$ \\
\hline \multicolumn{3}{|l|}{ Education (ref=degree) } \\
\hline No degree & $\mathbf{2 . 4 7} \mathbf{7}^{* * *}(2.04,3.00)$ & $1.92^{* * *}(1.67,2.20)$ \\
\hline \multicolumn{3}{|c|}{ Income level (ref=low income) ${ }^{\mathrm{b}}$} \\
\hline Middle income & $\mathbf{0 . 5 8}^{\star * *}(0.48,0.69)$ & $1.01(0.88,1.16)$ \\
\hline High income & $\mathbf{0 . 4 0}^{* * *}(0.32,0.50)$ & $\mathbf{0 . 7 5}^{* *}(0.63,0.90)$ \\
\hline Chronic condition $^{c}$ & $0.96(0.81,1.14)$ & $\mathbf{0 . 8 4} *(0.74,0.96)$ \\
\hline
\end{tabular}

Note: Boldface indicates statistical significance $\left({ }^{*} p<0.05,{ }^{* *} p<0.01\right.$, $\left.{ }^{* * *} p<0.001\right)$.

${ }^{a}$ Estimates are RRRs derived from multinomial logistic regression with SEs adjusted for clustering at the individual level and controlling for all characteristics presented. For all analyses, willing to vaccinate was the outcome reference group.

${ }^{\mathrm{b}}$ Households earning $<\$ 40,000$ a year were classified as low income, those earning $\$ 40,000-\$ 100,000$ were classified as middle income, and those above this threshold were classified as high income.

'Diagnosed with any of the following: diabetes, cancer, heart disease, kidney disease, asthma, chronic lung disease, and an autoimmune disease.

Obs., observations. of month-to-month changes confirmed that the likelihood of being undecided or unwilling to vaccinate (versus being willing to vaccinate) increased from April to October (Table 3 and Figure 1).

When all observations from the 13 survey waves were examined, those without a college degree were at elevated risk of being undecided or unwilling to vaccinate (undecided: $\mathrm{RRR}=2.47, \quad 95 \% \quad \mathrm{CI}=2.04,3.00$; unwilling: $\mathrm{RRR}=1.92,95 \% \mathrm{CI}=1.67,2.20$ ), as were Black participants (undecided: $\mathrm{RRR}=2.18,95 \%$ $\mathrm{CI}=1.73$, 2.74; unwilling: $\mathrm{RRR}=1.98,95 \% \mathrm{CI}=1.63$, 2.42) and female participants (undecided: $R R R=1.41$, $95 \% \quad \mathrm{CI}=1.20, \quad 1.65$; unwilling: $\mathrm{RRR}=1.29, \quad 95 \%$ $\mathrm{CI}=1.14,1.46)$. By contrast, a reduced risk of being undecided or unwilling to vaccinate was found among those aged $\geq 65$ years (undecided: $R R R=0.49,95 \%$ $\mathrm{CI}=0.38,0.63$; unwilling: $\mathrm{RRR}=0.61,95 \% \mathrm{CI}=0.51$, 0.74 ), those on high household incomes (undecided: $\mathrm{RRR}=0.40,95 \% \mathrm{CI}=0.32,0.50$; unwilling: $\mathrm{RRR}=0.75$, $95 \% \mathrm{CI}=0.63,0.90)$, and other race/ethnicity participants (undecided: $\mathrm{RRR}=0.57,95 \% \mathrm{CI}=0.40,0.82$; unwilling: $\mathrm{RRR}=0.52,95 \% \mathrm{CI}=0.39,0.71$ ).

An examination of the interactions between survey month and individual demographic characteristics did not yield evidence for systematic differences in changes in vaccination intentions over time between demographic groups. Furthermore, very similar associations were identified in a sensitivity analysis where willingness to vaccinate was treated as a continuous variable (Appendix Table 3, available online).

Finally, this study examined the attitudes toward the vaccine reported between October 14 and 31, 2020. The majority of the sample $(70 \%-80 \%)$ agreed that the COVID-19 vaccine would be personally beneficial, important for personal and community health, a good way to protect from COVID-19, and effective if approved by FDA or the Centers for Disease Control and Prevention (Table 1). However, responses differed markedly between those willing and those unwilling to be vaccinated. For example, whereas $92.4 \%$ of those who were willing to be vaccinated agreed that the vaccine would be effective if approved by FDA or Centers for Disease Control and Prevention, only $43.1 \%$ of those unwilling to be vaccinated agreed. In the overall sample, it was common for participants to report concerns over the vaccine, and $69.7 \%$ agreed that they were concerned about serious side effects of the vaccine. In total, $44 \%$ agreed that the vaccine might cause lasting health problems for them. However, such concerns were more prevalent among those unwilling to be vaccinated. For example, $65 \%$ of those unwilling to be vaccinated were concerned about lasting health problems resulting from the vaccine compared with $26.6 \%$ of those willing to be vaccinated. 


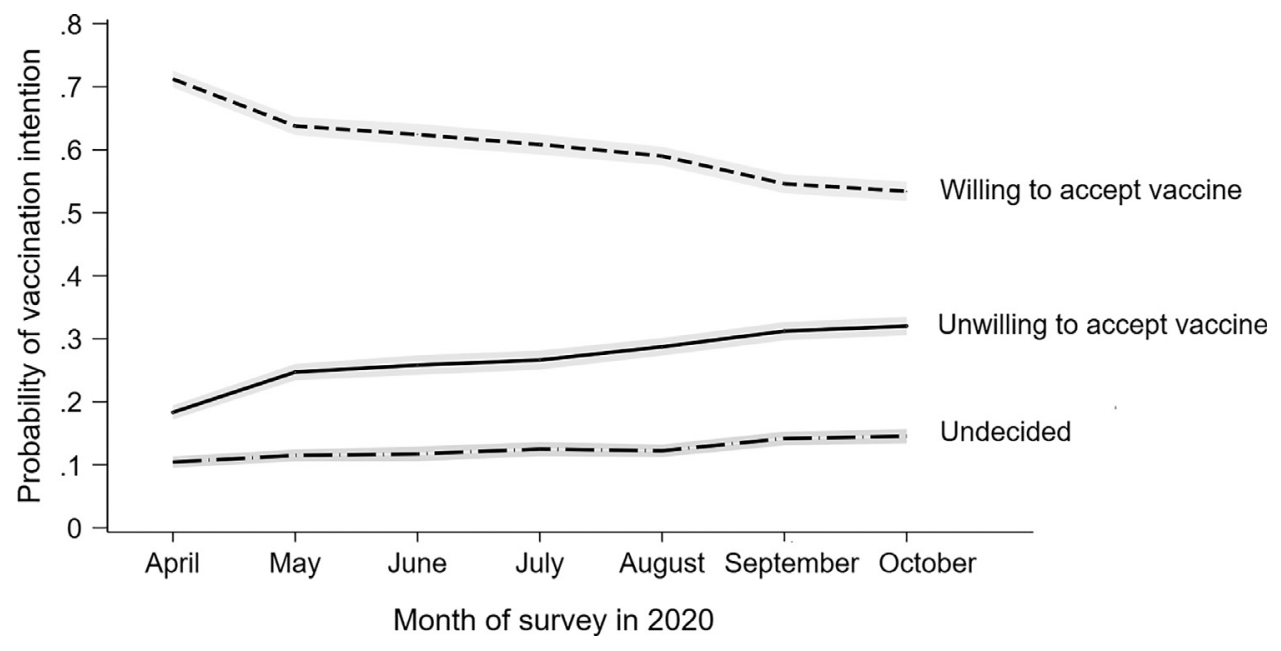

Figure 1. Change in vaccination intentions across the 13 waves of the Understanding America Study conducted between April 1 , 2020 and October 31, 2020.

Note: Graph is based on an analysis of 78,453 observations on 7,547 participants. Estimates are predicted probabilities from the marginal effects calculated after a multinomial logistic regression model adjusted for age, sex, race/ethnicity, household income, educational attainment, and the presence of pre-existing health conditions. $95 \% \mathrm{Cls}$ are presented in gray.

\section{DISCUSSION}

In a large nationally representative sample of U.S. adults, intentions to be vaccinated against COVID-19 have declined from a high of $71 \%$ of the population in April 2020 to close to only $54 \%$ reporting being willing to vaccinate in October 2020. Reporting being undecided or unwilling to vaccinate was more likely among those with lower levels of education and income as well as in female, Black (African American), and younger adults. Concerns about the vaccine causing long-lasting health problems and uncertainty about the benefits of the vaccine were also common.

On the basis of the estimates that vaccination coverage of close to $75 \%$ may be required to vaccinate to eradicate COVID-19, 4,5,10,29 the present estimates that are close to $50 \%$ of the population may be willing to vaccinate are concerning. It will now be critical to better understand the reasons why a large proportion of the population are skeptical about vaccination against COVID-19. Public concerns about the safety of vaccines may be an important driver of the increase in the proportion of the population reporting being unsure or explicitly stating that they will not vaccinate. ${ }^{10}$

In line with this, $70 \%$ of this study sample reported being concerned about serious side effects of the vaccine, and $44 \%$ believed that a vaccine might cause lasting health problems for them. To some extent, these concerns are to be expected given the unprecedented speed at which vaccines have been developed. ${ }^{2,3}$ However, the rise of anti-vaccination misinformation (e.g., misleading healthcare information, conspiracy theories) and political polarization may also have played a role in explaining this increase. ${ }^{11-1429}$ It will therefore be critical that accurate safety information is widely and transparently communicated by trusted sources to promote confidence in the scientific decision making underpinning the approval of COVID-19 vaccines. ${ }^{16,21}$

It will also be important to address social inequalities in vaccination intentions ${ }^{20,21}$ and to ensure widespread uptake of effective COVID-19 vaccines. In this study, willingness to vaccinate was strikingly lower among more disadvantaged groups (e.g., African Americans and those with lower income and education levels), and these groups have already been disproportionately affected by COVID-19. ${ }^{18,19}$ Previous research on influenza vaccines also suggests that access issues may prevent minority and disadvantaged groups from being vaccinated. ${ }^{21,30}$ It will therefore be important to identify the strategies to reduce social inequalities in both vaccination intentions and opportunities to vaccinate. ${ }^{20}$

The strengths of this research include the use of a large probability-based nationally representative sample of adults, allowing generalizations to be made to the population. This study also moves beyond previous research ${ }^{6-10}$ by including a high-frequency longitudinal assessment of vaccination intentions throughout the pandemic. In addition, participant concerns and perceptions of the benefits of a potential vaccine were assessed to shed light on potential reasons for the low willingness to vaccinate.

\section{Limitations}

A limitation of the UAS is the potential lack of representation of those who do not speak either English or 
Spanish and those not comfortable engaging with online surveys. In addition, this study is limited in its reliance on self-reported intentions about a hypothetical vaccine and the lack of detailed assessment of factors that may explain why vaccination intentions have declined over time in the U.S. However, in advance of the deployment of a COVID-19 vaccine, it has been necessary to rely on intention-based measures that have been shown to predict vaccination behavior. ${ }^{30}$ Furthermore, intentions are malleable and represent a target for evidence-based approaches aiming to increase the proportion of the population who are willing to vaccinate. ${ }^{31}$ This now represents an urgent public health priority to minimize further loss of life due to the COVID-19 pandemic. It is also essential that research aiming to modify vaccination uptake is theory based and informed by relevant models such as the Health Belief Model, ${ }^{32}$ which provides a framework for understanding the factors that may shape vaccination intentions (e.g., perceived benefits and barriers, perceived susceptibility to COVID-19) and future behavior.

Finally, now that vaccines are authorized and information on their effectiveness and safety is available, it is crucial that studies track vaccination attitudes (e.g., perceived health benefits and side effects, social norms relating to vaccination) to provide an in-depth understanding of how vaccine intentions and uptake change as vaccines are deployed. Initial research suggests that willingness to vaccinate may have increased in November when the availability of viable vaccines appeared imminent. ${ }^{33}$

\section{CONCLUSIONS}

Intentions to be vaccinated against COVID-19 have declined rapidly during the pandemic, and in October 2020, close to half of Americans were undecided or unwilling to be vaccinated. This reduced willingness to vaccinate may undermine the pandemic response and the public health benefits of an effective vaccine.

\section{ACKNOWLEDGMENTS}

The project described in this paper relies on data from the survey(s) administered by the Understanding America Study (UAS), which is maintained by the Center for Economic and Social Research at the University of Southern California. The content of this paper is solely the responsibility of the authors and does not necessarily represent the official views of the University of Southern California or UAS.

The collection of the UAS coronavirus disease 2019 (COVID19) tracking data is supported in part by the Bill \& Melinda Gates Foundation and by Grant U01AG054580 from the National Institute on Aging. However, these organizations bear no responsibility for the analysis or interpretation of the data.
MD had full access to the study data and takes responsibility for the integrity of the data and accuracy of the data analysis. MD and ER participated in the conceptualization and design of the study; acquisition, analysis, or interpretation of data; drafting of the manuscript; and critical revision of the manuscript for important intellectual content. Statistical analysis was performed by MD.

ER has previously received funding from Unilever and the American Beverage Association for unrelated research. No other financial disclosures were reported.

\section{SUPPLEMENTAL MATERIAL}

Supplemental materials associated with this article can be found in the online version at https://doi.org/10.1016/j. amepre.2021.01.008.

\section{REFERENCES}

1. Weekly epidemiological update - 9 February 2021. WHO; 2021. https://www.who.int/publications/m/item/weekly-epidemiologicalupdate—-february-2021. Accessed February 10, 2021.

2. Lurie N, Saville M, Hatchett R, Halton J. Developing COVID-19 vaccines at pandemic speed. N Engl J Med. 2020;382(21):1969-1973. https://doi.org/10.1056/NEJMp2005630.

3. U.S. Food and Drug Administration. FDA takes additional action in fight against COVID-19 by issuing Emergency Use Authorization for second COVID-19 vaccine. U.S. Food and Drug Administration. December 18, 2020. https://www.fda.gov/news-events/press-announcements/fda-takesadditional-action-fight-against-covid-19-issuing-emergency-use-authorization-second-covid. Accessed December 22, 2020.

4. Bartsch SM, O'Shea KJ, Ferguson MC, et al. Vaccine efficacy needed for a COVID-19 coronavirus vaccine to prevent or stop an epidemic as the sole intervention. Am J Prev Med. 2020;59(4):493-503. https:// doi.org/10.1016/j.amepre.2020.06.011.

5. Iboi EA, Ngonghala CN, Gumel AB. Will an imperfect vaccine curtail the COVID-19 pandemic in the U.S.? Infect Dis Model. 2020;5:510524. https://doi.org/10.1016/j.idm.2020.07.006.

6. Lazarus JV, Ratzan SC, Palayew A, et al. A global survey of potential acceptance of a COVID-19 vaccine [published correction appears in Nat Med. 2021;27(2):354]. Nat Med. 2021;27(2):225-228. https://doi. org/10.1038/s41591-020-1124-9.

7. Dodd RH, Cvejic E, Bonner C, Pickles K, McCaffery KJ. Sydney Health Literacy Lab COVID-19 group. Willingness to vaccinate against COVID-19 in Australia. Lancet Infect Dis. 2020 In press. Online June 30. https://doi.org/10.1016/S1473-3099(20)30559-4.

8. Wang J, Jing R, Lai X, et al. Acceptance of COVID-19 vaccination during the COVID-19 pandemic in China. Vaccines. 2020;8(3):482. https://doi.org/10.3390/vaccines8030482.

9. Taylor S, Landry CA, Paluszek MM, Groenewoud R, Rachor GS, Asmundson GJG. A proactive approach for managing COVID-19: the importance of understanding the motivational roots of vaccination hesitancy for SARS-CoV2. Front Psychol. 2020;11:575950. https://doi. org/10.3389/fpsyg.2020.575950.

10. Fisher KA, Bloomstone SJ, Walder J, Crawford S, Fouayzi H, Mazor KM. Attitudes toward a potential SARS-CoV-2 vaccine: a survey of U.S. adults. Ann Intern Med. 2020;173(12):964-973. https://doi.org/ 10.7326/M20-3569.

11. Romer D, Jamieson KH. Conspiracy theories as barriers to controlling the spread of COVID-19 in the U.S. Soc Sci Med. 2020;263:113356. https://doi.org/10.1016/j.socscimed.2020.113356.

12. Kata A. A postmodern Pandora's box: anti-vaccination misinformation on the Internet. Vaccine. 2010;28(7):1709-1716. https://doi.org/ 10.1016/j.vaccine.2009.12.022. 
13. Roozenbeek J, Schneider CR, Dryhurst S, et al. Susceptibility to misinformation about COVID-19 around the world. R Soc Open Sci. 2020;7 (10):201199. https://doi.org/10.1098/rsos.201199.

14. Allcott H, Boxell L, Conway J, Gentzkow M, Thaler M, Yang D. Polarization and public health: partisan differences in social distancing during the coronavirus pandemic. J Public Econ. 2020;191:104254. https:// doi.org/10.1016/j.jpubeco.2020.104254.

15. Neumann-Böhme S, Varghese NE, Sabat I, et al. Once we have it, will we use it? A European survey on willingness to be vaccinated against COVID-19. Eur J Health Econ. 2020;21(7):977-982. https://doi.org/ 10.1007/s10198-020-01208-6.

16. Bauchner H, Malani PN, Sharfstein J. Reassuring the public and clinical community about the scientific review and approval of a COVID19 vaccine. JAMA. 2020;324(13):1296-1297. https://doi.org/10.1001/ jama.2020.18860.

17. Fancourt D, Steptoe A, Wright L. The Cummings effect: politics, trust, and behaviours during the COVID-19 pandemic. Lancet. 2020;396 (10249):464-465. https://doi.org/10.1016/S0140-6736(20)31690-1.

18. Townsend MJ, Kyle TK, Stanford FC. Outcomes of COVID-19: disparities in obesity and by ethnicity/race. Int J Obes (Lond). 2020;44 (9):1807-1809. https://doi.org/10.1038/s41366-020-0635-2.

19. Lamb MR, Kandula S, Shaman J. Differential COVID-19 case positivity in New York City neighborhoods: socioeconomic factors and mobility. Influenza Other Respir Viruses. 2020 In press. Online October 14. https://doi.org/10.1111/irv.12816.

20. Endrich MM, Blank PR, Szucs TD. Influenza vaccination uptake and socioeconomic determinants in 11 European countries. Vaccine. 2009;27(30):4018-4024. https://doi.org/10.1016/j. vaccine.2009.04.029.

21. Galarce EM, Minsky S, Viswanath K. Socioeconomic status, demographics, beliefs and A (H1N1) vaccine uptake in the United States. Vaccine. 2011;29(32):5284-5289. https://doi.org/10.1016/j.vaccine.2011. 05.014.

22. Reiter PL, Pennell ML, Katz ML. Acceptability of a COVID-19 vaccine among adults in the United States: how many people would get vaccinated? Vaccine. 2020;38(42):6500-6507. https://doi.org/10.1016/j.vaccine.2020.08.043.

23. Alattar L, Messel M, Rogofsky D. An introduction to the Understanding America Study internet panel. Soc Sec Bull. 2018;78(2):13-28. https://www.ssa.gov/policy/docs/ssb/v78n2/v78n2p13.html.
24. Kapteyn A, Angrisani M, Bennett D, et al. Tracking the effect of the COVID-19 pandemic on the lives of American households. Surv Res Methods. 2020;14(2):179-186. https://doi.org/10.18148/srm/2020. v14i2.7737.

25. Kim JK, Crimmins EM. How does age affect personal and social reactions to COVID-19: results from the national Understanding America Study. PLoS One. 2020;15(11):e241950. https://doi.org/10.1371/journal.pone.0241950.

26. Robinson E, Daly M. Explaining the rise and fall of psychological distress during the COVID-19 crisis in the United States: longitudinal evidence from the Understanding America Study. Br J Health Psychol. 2020 In press. Online December 5. https://doi.org/10.1111/bjhp.12493.

27. Daly M, Robinson E. Psychological distress and adaptation to the COVID-19 crisis in the United States. J Psychiatr Res. 2020 In press. Online October 27. https://doi.org/10.1016/j.jpsychires.2020.10.035.

28. Allison PD. Logistic Regression Using SAS: Theory and Application. 2nd ed. Cary, NC: SAS Institute, 2012.

29. The Royal Society and the British Academy. COVID-19 vaccine deployment: Behaviour, ethics, misinformation and policy strategies. https://royalsociety.org/-/media/policy/projects/set-c/set-c-vaccine-deployment.pdf. Published October 21, 2020. Accessed March 23, 2021.

30. Schmid P, Rauber D, Betsch C, Lidolt G, Denker ML. Barriers of influenza vaccination intention and behavior - a systematic review of influenza vaccine hesitancy, 2005 - 2016. PLoS One. 2017;12(1):e0170550. https://doi.org/10.1371/journal.pone.0170550.

31. Wegwarth O, Kurzenhäuser-Carstens S, Gigerenzer G. Overcoming the knowledge-behavior gap: the effect of evidence-based HPV vaccination leaflets on understanding, intention, and actual vaccination decision. Vaccine. 2014;32(12):1388-1393. https://doi.org/10.1016/j. vaccine.2013.12.038.

32. Wong LP, Alias H, Wong PF, Lee HY, AbuBakar S. The use of the health belief model to assess predictors of intent to receive the COVID-19 vaccine and willingness to pay. Hum Vaccin Immunother. 2020;16(9):22042214. https://doi.org/10.1080/21645515.2020.1790279.

33. Funk C, Tyson A. Intent to get a COVID-19 vaccine rises to $60 \%$ as confidence in research and development process increases. Pew Research Center. 2020 December 3 https://www.pewresearch.org/science/2020/12/03/intent-to-get-a-covid-19-vaccine-rises-to-60-as-confidence-in-research-and-development-process-increases/ . Accessed December 22, 2020. 